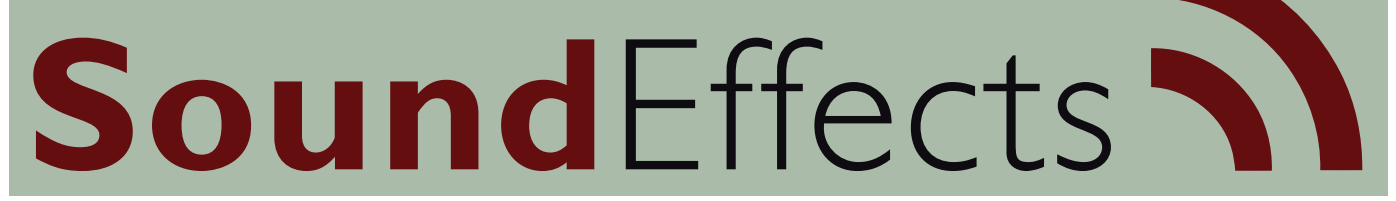

An Interdisciplinary Journal of Sound and Sound Experience

\title{
Emma Tornborg
}

\section{Sound and stasis in pictorial poetry}

\author{
Emma Tornborg \\ Ph.D. Student \\ School of Language and Literature \\ Linnaeus University \\ emma.tornborg@Inu.se
}




\begin{abstract}
In this article I investigate how various representations of sound influence temporality and imagery in pictorial poetry. Literary pictorialism can be defined as a phenomenon that occurs when the fictional reality, psychological or physical, in a text is represented as image. A pictorial poem often revolves around one single image and the poem's subject matter, a scene or a landscape for example, is described as silent and static; the poem is composed in a way that can lead the reader to create a stable mental image of its subject matter. The introduction of sound into such a poem can have various effects; one being that the static mood of the poem is interrupted. It can have other results as well, depending on the kind of sound. Sound can, for example, be represented as a concrete and tangible object, in which case it becomes part of the visual scene represented in the poem. A cognitive approach is used to illustrate and explain the relation between sound and sight in pictorial poetry.
\end{abstract}

"Painting is there all at once. When I read a book, listen to music, or go to a movie, I experience these works over time. A novel, a symphony, a film are meaningful only as a sequence of words, notes, and frames. Hours may pass but a painting will not gain or lose any part of itself. It has no beginning, no middle, and no end. I love painting because in its immutable stillness it seems to exist outside time in a way no other art can. The longer I live the more I would like to put the world in suspension and grip the present before it's eaten by the next second and becomes the past. A painting creates an illusion of an eternal present, a place where my eyes can rest as if the clock has magically stopped ticking". (Hustvedt, 2005, p. xv)

\title{
Introduction
}

Investigating the presence of sound in pictorial texts can at first seem paradoxical, since literary pictorialism, which I define as 'a phenomenon that occurs when the fictional reality, psychological or physical, in a text is represented as image, is associated mainly with the imitation of or reference to silent, visual and static artefacts such as paintings, sculptures and photographs. However, sound is sometimes represented in pictorial texts, and when that occurs it is often spatialised and concretised, represented as an object in space, and given properties associated with objects, such as colour, shape and form. ${ }^{1}$ The most famous Swedish example is perhaps 'Vädertavla' ('Weather Picture') by Tomas Tranströmer (2002 p. 45): 'Ett hundskalls hieroglyph står målad/i luften över trädgården' ('A dog’s barking is a hieroglyph/painted in the air above the garden') (Tranströmer, 2006, p. 29). Concretising sound is, however, not the only way to represent it, and my aim in this article is to discuss the various ways that sound can be represented in pictorial poetry and what its functions are. The basic assumption is that all media products contain 
traces of other media, modalities and modes, a relation W.J.T. Mitchell has famously described as 'all media are mixed media' (2005, p. 260).

I intend to address two issues: What is pictorial poetry, and how can sound be represented in this kind of poetry? These subjects will be approached by means of intermedial theory and, to some extent, cognitive science. ${ }^{2}$ The poems analysed are written by Swedish poets Tomas Tranströmer, Lars Gustafsson and Ella Hillbäck. The hypothesis is that sound can be represented in various ways in pictorial poetry and that the mode of representation affects the poems in two respects first and foremost: how they represent time and how they conjure up mental images in the mind of the reader.

\section{Some aspects of pictorial poetry}

Words on a page do not normally resemble the physical objects they refer to unless shaped in patterns or forms, as in emblematic literature and some concrete poetry. Colin Lyas writes, 'a collection of words, a novel say, does not visually resemble any world, either actual or possible' (2001, p. 176). However, they can conjure up images in our minds that bear a likeness to the objects they refer to. This can be achieved in different ways, some of which I will examine more closely in this article.

\section{Virtual time and virtual timelessness}

A noteworthy subcategory of works which refer to time would be works that are about time in the sense that they project, sometimes surprisingly, a sense of timelessness. (Levinson \& Alperson, 1991, p. 443)

Pictorial poetry imitates and/or refers to media products that are static in their material modality, such as paintings, sculptures and photographs. Therefore, it is important that a reduction of movement occurs in the poem. In his book The Sister Arts; The Tradition of Literary Pictorialism and English Poetry from Dryden to Gray (1958), Jean Hagstrum states:

The pictorial in a verbal medium necessarily involves the reduction of motion or stasis or something suggesting such a reduction. It need not eliminate motion entirely, but the motion allowed to remain must be viewed against the basic motionlessness of the arrangement. (pp. xxi-xxii)

Virtual time is created when a medium's sense data encourages us to include time passing in the interpretation (Elleström, 2010). For instance, a photograph, although static in its material modality, can give the impression of time passing; that sense of time is called virtual time. Looking at a snapshot in which a running person is represented, you may include movement and thereby time passing in your interpretation, 
even though the photograph in itself is completely still. The fact that the photograph, static in its material modality, can represent movement underlines both its stasis and the perceived movement and temporality. Time passing in a novel is virtual as well; a book can relate events taking place over several years or only one day. The temporal flux is mediated by the novel, which in itself, as all printed text, is static in its material modality. Even so, we are used to consider a novel or a poem temporal media, since the basic form of language is oral. When a novel or a poem is being recited, the sense data unfolds in time, and the listener cannot see what came before or what will come. We must therefore take into consideration the fact that although ink on paper is static in itself, we usually interpret literature as sequential and temporal.

Printed literature has at least two kinds of temporalities: the actual time it takes to read, for example, James Joyce's Ulysses (for some people perhaps a lifetime) and the virtual time it represents (in this case only one day). A text can represent a billion years in one sentence or half a second in a thousand words. As a consequence literature must be able to represent virtual time not passing, that is to say, virtual timelessness. A temporal medium representing timelessness is not as paradoxical as it first may seem, if we consider timelessness simply one end of a temporal continuum, where infinity is the other.

Research has shown that verbal text can influence the mobility of mental representations (Richardson \& Matlock, 2007). One example is fictive motion (FM). There are indications that we tend to look longer at a picture if it is described by fictive motion. The sentence 'The road goes through the desert' includes metaphorical movement, in contrast to the sentence 'The road is in the desert', in which no movement exists:

We have found suggestive evidence that fictive motion descriptions can have an immediate and distinct effect on visual processing. Matlock and Richardson (2004) presented participants with simple drawings of paths such as roads, rivers, and pipelines. They heard either FM or non-FM descriptions of these paths while their gaze was tracked. The FM descriptions caused participants to spend more time inspecting the region of the path. (Richardson \& Matlock, 2007, p. 31)

It seems that we tend to give more attention to movement than to stasis. What is relevant for this article is that the findings show that we actually react differently depending on whether a description contains motion verbs or not.

Adjectives that describe silence and stillness can create virtual timelessness in a text, as can adjectives that describe objects visually (colour, size, shape etc.). Verbs influence how we perceive action and movement, or lack thereof. Stasis is evoked if the number of motion verbs, such as run, walk and fly, are reduced, as well as other verbs that describe physical action, such as jump, shake and so on. In some pictorial texts the passive verb form is used instead of the active form ('he is dreaming' instead of 'he dreams'). 


\section{Static composition}

Literary texts can represent stasis and timelessness if their structure imitates the static composition of paintings or other static two- or three-dimensional visual artefacts such as photographs or sculptures: 'Pictorialism generates in language effects similar to those created by pictures' (Heffernan, 1993, p. 3). If verbs govern movement, nouns function as the building blocks of our mental imagery. As James T. Enns (2004) has pointed out, we easily form mental images of concrete nouns, as opposed to verbs or abstract concepts. Prepositions, on the other hand, help us to create mental representations of spatial properties:

Prepositions can be viewed as instructions on the placement and distribution of attention over entities in the mental simulation. For example, in one reading of 'on', this preposition places one entity above the other and makes it the focal entity, whereas 'under' makes the lower entity the focal one. (Zwaan, 2003, p. 51)

Bergen and Wheeler (2009) conclude 'that while content words tell understanders what to mentally simulate and what brain regions to use in performing these simulations, grammatical constructions such as aspect modulate how those simulations are performed' (p. 150). In pictorial poetry, the subject matter is often presented so that it reminds us of the composition of a picture, with prepositions that place objects in space or point to direction: up, down, over, under, on etc.

Another aspect of the structuring of pictorial poetry is framing. An introductory invitation to the reader to see (for example 'behold', 'look', 'see') can function as a framing, as can titles that in some way refer to pictures or other visual media, for example the title of one of Wisława Szymborska's poems, 'Photograph from September 11'. A description can also be verbally framed if the same word or phrase is used in the beginning of the poem and at the end. ${ }^{3}$ Very common and important components of pictorial texts are vivid descriptions of the poem's subject matter, references to pictures or painters, to art genres or photographic or painterly techniques, and intermedial similes such as 'statue-like' or 'pretty as a picture'. Vivid descriptions, references and similes are more concerned with the semantic content of the pictorial text than with its form and structure, but all aspects are equally important. A pictorial text seldom contains all these aspects, but no pictorial text lacks them completely.

\section{Mental imagery and verbal media}

My focus in this article is to investigate the equivalence of poetry to visual image, where one static image is represented to us, framed and almost hanging in front of us like in the museum. This requires that the text is short, since longer texts often represent more than one or two images, and a large number of images will 
result in a flow of images passing through our minds while we read, mixed together, blurred, and thereby less perceivable and harder to remember. Concentration on one single image is typical for the poetics of Lars Gustafsson, a subject on which he has reflected repeatedly: 'Metaphors, heaped on each other, while seeking the same end of visibility very often result in abstractions since none of the pictures implicit in them can be concentrated on before it is made obsolete by the next one' (originally in English; in: Söderström, 2003, p. 23). Short poems or short excerpts from longer texts can conjure up single, vivid and detailed images that we as readers can recreate in our mind's eye. In other words, I focus on the moment when the reader becomes the beholder, as it were, when the reader creates a mental image of the object, person or landscape. ${ }^{4}$

Mental imagery can be defined as 'the mental invention of an experience that at least in some respects resembles the experience of actually perceiving an object or an event either in conjunction with, or in the absence of, direct sensory stimulation' (Johansson, 2011, p. 11). Much research that has been done on the subject shows that we process mental images and perceived external stimuli similarly. In one research report (Reddy, Tsuchiya \& Serre, 2009, p. 818) the authors write that 'the patterns of representation during imagery and actual viewing are in fact surprisingly similar to each other', and an experiment conducted by cognitive researchers Gregoire Borst and Stephen M. Kosslyn showed that 'mental images and perceived stimuli are represented similarly and can be processed in the same way' (2008, p. 849).

Do we need cognitive science in analysing and interpreting literary texts? The answer is perhaps 'we do not'. Literature was studied and analysed long before cognitive science was invented. However, cognitive science, and especially research on mental imagery, can serve as an indicator to point us, literary researchers, in the right direction. Early studies of literary pictorialism, for example John B. Bender's Spenser and Literary Pictorialism from 1972, often contain theories that we can now find in cognitive science. Bender was aware of the risks associated with comparing the visual and the verbal arts, and his aim was not to find formal similarities between the two, but to investigate "how words can be selected and organized to imitate the process of visual perception, not how paintings as such can be made of words' (pp. 23f.; emphasis in original). Today we have some evidence that he was right, that mental images evoked by verbal stimuli, for example literature, could be quite vivid and contain temporal and spatial properties.

One way to learn more of the nature of mental imagery is by means of eye movement tracking. Cognitive researcher Jana Holšánová (2008) describes an experiment where the participants first listened to a verbal description and then retold it from memory while their eye movements were measured. The results show that the eye movements were consistent with the spatial arrangements of the described image. The participants moved their eyes while retelling the description and used their 
gaze and eye movements to 'paint' the imagined picture in front of them. The participants could shrink, enlarge or stretch out the mental representation, but the eye tracking revealed that the majority still placed the objects in correct relation to each other. Moreover, there was no difference in eye movements between participants who described a picture they had seen and participants who described a picture that had been described to them. This eye movement experiment strongly indicates that we do not have to see a picture to create a mental representation of it; reading or hearing a description of it is enough.

This, one could argue, is valid for all mental images and memories and, thereby, not limited to inner representations of framed visual artefacts such as paintings. The aim here, however, is not to prove that all inner images function as paintings in a gallery, but that the inner image can be created by means of verbal description as well as of picture viewing. What we remember when we read or listen to a verbal description is not solely the words, but the image they conjure up in our minds. This has been noted in studies by several cognitive researchers: 'A primary property of mental models is that they represent what the text is about (events, objects, and processes described in the text), rather than features of the text itself' (Glenberg, Mayer \& Lindem, 1987, p. 69); 'Readers tend to remember the mental model they constructed from a text, rather than the text itself' (Bower \& Morrow, 1990, p. 44); and Zwaan \& Radvansky write:

\footnotetext{
When we read a newspaper article about a particular event, we may come away with a similar understanding of that event as when we had seen it in a news report on television. Given the very different nature of these modalities, this is impossible to explain if we do not assume that readers construct a mental representation of the event itself rather than of the medium that described the event. There is empirical evidence that supports this intuition. (1998, p. 164)
}

Of course, this is not true for every reader or all literature on all occasions. Concrete poetry, for instance, is sometimes impossible to read conventionally, and we would probably remember not only its content but how the words were arranged on the paper as well. Novels, on the other hand, are too extensive and too narrative to be reduced to one static image in our minds. When it comes to the readers, it is important to note that the ability to form images as well as the format of the mental images vary (Kozhevnikov, Kosslyn \& Shephard, 2005). Kozhevnikov et al. show that for example engineers are better at constructing spatial representations that include location, and that they process the image part by part, whereas visual artists, for example, are better at mentally representing shape and colour, and that they perceive objects holistically. These findings only underline what we already know, namely that interpretations and reactions differ among readers. This does not mean that there are no similarities. As many experiments in the field of cognitive 
science show, we are more alike than we might think. This insight also forms the basis of the field of literary research: if we did not share some basic form of understanding of literary texts, we would never be able to produce any relevant research.

\section{Representation of sound}

The notion that sound is a particular immediate or direct medium is not new. On the contrary, if we lend an ear to the many voices of the disparate field of sound studies, a recurrent theme is the question of how listening to the world conditions our experience of it in a fundamentally different way than seeing. It is claimed that we look through our eyes, but sound enters our ears, and therefore seeing creates a distance to the perceived, while sound immerses us in it. (Vandsø, 2011, p. 71)

What does it mean to say that we can distance ourselves from things that we see, but that we become immersed in sound? One answer is that we can close our eyes and decide not to look, but it is harder to keep sound out; it enters through our ears even if we cover them. Furthermore, compared to visible objects, which we can see even if they move, sound is elusive and can bounce, which makes it harder for us to discern where it comes from. Browsing the research databases for articles about literature and sound, one often ends up in the fields of metrics and sound patterns. These are, of course, obvious fields of interest for this specific intermedial relation; music and poetry share the same history and were for a long period of time basically the same thing. What concerns us here, however, is not the relation between music and poetry, but the representation of the relation between sound and image in poetry.

The alphabet is essentially a system of signs that represent the phonemes. Letters of the alphabet represent, in other words, the sounds that we use when we speak. In that respect, 'representation of sound' simply means letters and words. But there is another way of representing sound in text, and that is to use words that signify various kinds of sound: noise, barking, screaming etc., words that are not only sound, but semantically mean sound. When I refer to representations of sound, I do not mean words or letters in general, but words that signify specific sounds.

Since media that include sound in their material modality (music, theatre, film etc.) are temporal (Elleström, 2010), the introduction of virtual sound (representations of music, bird song, general noise) in a poem would normally create virtual time. However, as stated above, descriptive poems that represent conditions rather than actions, images rather than events (for example, pictorial poems that imitate the static property of still images), often represent sound, especially sudden and sharp sound like animal shrieks, as visually perceived and static objects.

'[M]ost fictional imagery is, like our language itself, overwhelmingly visual', Stephen J. Adams writes in his article about Henry Roth's novel Call it sleep (Adams, 1989, p. 43). Maybe the historical preference for sight over sound in our Western 
culture is the reason why poetry dealing with sight and sound from time to time transforms what you can hear into what you can see. Representation of sound as visible object is also, of course, a poetic choice; due to the heterogeneous properties of sight and sound it can have an estranging effect.

Often the treatment of sound in poems differs, depending on what kind of sound it is. An ongoing sound, like the sound of waves or of wind blowing in the trees, does not interrupt the static feeling in a poem in the same way as, for example, a dog's bark or someone's voice might do. Wind in the trees becomes more of a soundtrack, a slow background noise that does not have a distinct beginning or end. Therefore, the (virtual) presence of that kind of sound in a virtual timeless poem does not seem to require or result in any specific change in the poem's 'stimmung'. On the contrary, it can be made a part of the still and silent world represented in the pictorial poem. Other types of sound that can be represented in a poem without changing the static mood are sounds that conjure up associations to something frozen or rigid.

A bird's shriek, on the other hand, is a short, sharp sound that begins and ends within a second. If such a sound is represented in a poem it can sometimes interrupt the meditative mood and seem to break loose from and change the whole environment and, thereby, be used as a mood changer. However, it can have other functions as well. If the sound is concretised into a tangible and visible object, like something that can be captured, seen or touched, then the opposition between time and timelessness, silence and sound, disappears and all the objects in the poem can be treated as being on the same level. ${ }^{5}$ This can be observed in Tranströmer's poem above, where the dog's barking is turned into a painted hieroglyph. Tranströmer often colours sound, as in the poem 'Morgonfåglar' ('Morning Birds') (Tranströmer, 2001, p. 109): 'Jag sätter på mig solglasögonen./Fågelsången mörknar' ('I put on my sunglasses./The birdsong darkens') (Tranströmer, 2006, p. 79). In an untitled poem by Lars Gustafsson (1998, p. 21), a bird is described as 'ett mörkt och spetsigt utropstecken' ('a dark and pointy exclamation mark') (my translation). Here the exclamation mark refers both to the noise and to the animal that makes it. Another example, where sound is described as having properties associated with objects (such as colour, shape and weight), is Elizabeth Bishop's (2011, p. 67) poem 'View of the Capitol from The Library of Congress': 'Catching the music in their leaves/like gold-dust, till each big leaf sags'?

\section{Analyses}

The pictoriality of the analysed poems consists of adjectives that describe stasis as well as shape, colour and form, a lack of motion verbs, references to visual media products and framing. The first poem to be analysed is 'Sista bild' ('Last Picture') by Lars Gustafsson, (1998, p. 63), originally published in 1962. 
'Sista bild'

Uppbrott och skymning

vinden kantrar och hastiga steg.

I vacklande flockar bryter fåglarna upp

och jag hade aldrig trott de var så många.

Men den egentliga världen är alldeles stilla, blåsten stelnad i träden med styvnade kronor

flaggorna spretar under orörliga moln och uppförstorad avvaktar en avlägsen storm.

Det klirrar av uppbrott och skymning.

Men myntet som han tappade, en mörkklädd man, som var bleklagd med utdraget ansikte, det klirrar ännu mot golvet av marmor.

Om han når det är han förlorad.

'Last Picture'

Departure and dusk

the wind veers and hasty steps.

The birds take off in staggering flights

and I never would have thought that they were so many.

But the real world is completely still.

the wind fixed in the trees with rigid crowns

the flags sprawl under motionless clouds

and a distant storm awaits, magnified.

There is clinking of departure and dusk.

But the coin he dropped, the man dressed in black,

with a pale and drawn out face,

still clinks on the marble floor.

If he reaches it, he'll be lost. ${ }^{8}$

The poem's title prompts us to create a mental image of what the poem describes. Prompting the reader to see does not function solely as an aesthetic device; it has a cognitive function as well. Zwaan and Radvansky (1998) conclude that although 'people are capable of constructing rather detailed mental images from verbal descriptions', it is not something one automatically does; 'creating a detailed mental image requires extensive and effortful processing. For example, it takes several 
exposures to a text to construct a spatial image'. Moreover, 'there is also evidence suggesting that readers do not construct detailed spatial representations unless explicitly instructed to do so' (Zwaan \& Radvansky, 1998, p. 178). A poem often requires both reflection and several readings to be fully grasped, and a title that in some way requests the reader to see functions as an instruction to the reader.

The first stanza has a framing role, since the title has the word 'picture' in it," and since the first stanza sets the scene for the next stanza. Moreover, the next stanza starts with the word 'but', which connects the first with the second. The second stanza is a manifestation of a world with absolutely no actual movement. It is 'completely still'. The wind does not blow; it is 'fixed in the trees', and the trees' crowns are 'rigid'. The flags do not flutter, they are 'sprawled', and the clouds are 'motionless'. The storm 'awaits' - a verb that signals hesitation and arrested movement - in the distance, 'magnified', which is a word that creates associations to photographic techniques more than to a power of nature. It also raises questions about perspectives: magnified in relation to what? It seems that the poem's perspective is set, like that of a painting or a photograph.

What we see here is a poem representing movement in the same way that a picture depicts motion. The motion is not articulated, but merely indicated by the shape of the flags, the rigid crowns of the trees etc. Literary time and motion are of course virtual as well, but they differ from the spatiotemporal virtuality of the visual arts; what the former says by means of symbols, the latter shows by means of icons and indexes. When such iconic indications of movement appear in a poem instead of in a painting, the virtual time paradoxically stops; the paradox occurs, because manifestations of time and movement differ between media, and a verbal description of a still image representing movement does not represent movement in itself. So, to be exact, the poem conveys the still image's virtual movement and not the verbal text's virtual movement.

With movement comes time. With stasis comes timelessness. The first part of the second stanza is an excellent example of the notion of virtual timelessness, the sensation of arrested time in verbal texts. The last part of the second stanza, which is semantically connected to the last line of the poem, introduces sound to the poem. As we know, the introduction of sound might trigger temporal flux; the fictive world is no longer static. However, there are several ways to represent sound, and there are several different kinds of sound as well.

The verb 'clink' in 'Sista bild' is the only word that directly refers to sound. 'Hasty steps' may be audible but they can also be silent. 'Clink' can create associations to something cold and frozen, like ice crystals, or to something metallic; at least this is true for the Swedish word 'klirra'. Even though the sound is sharp and disturbing, it does not change the feeling of rigidness in the poem. Partly because 'clink' has a cold and frozen feeling to it, partly because it seems like it does not stop; the 
clinking will go on until the man reaches the coin, and he might never succeed. The same temporal paradox is found in the poem 'Ode on a Grecian Urn' by John Keats. A movement, which goes on forever because it is frozen in time, transforms into stasis, even more so since it was originally the opposite; a paradox creates stagnation, because it never resolves. The coin is a word with multiple symbolic connotations, which is also true for the character of the pale man dressed in black. One possible interpretation is that the man is a symbolic figure, not of this world and, therefore, not a part of the landscape described in the poem. But just like the landscape, he seems to be locked in position - maybe he will never reach the coin he dropped; maybe it will be clinking on the floor for all eternity.

In the poem 'Dygnskantring' ('Midnight Turning Point') (Tranströmer, 2006, p. 12) the presence of different sounds creates various effects:

'Dygnskantring'

Stilla vaktar skogsmyran, ser i intet

in. Och intet hörs utom dropp från dunkla

lövverk och det nattliga sorlet djupt $\mathrm{i}$

sommarens canyon.

Granen står som visaren på ett urverk, taggig. Myran glöder i bergets skugga.

Fågel skrek! Och äntligen. Långsamt börjar molnforan rulla.

'Midnight Turning Point'

The wood ant watches silently, looks into nothing. And nothing's heard but drips from dim

leafage and the night's murmuring deep in summer's canyon.

The spruce stands like the hand of a clock, spiked. The ant glows in the hill's shadow. Bird cry! And at last. The cloud-packs slowly begin to roll.

The poem provides an example of how a sudden sharp noise might result in the interruption of stasis. Nothing in this poetic world moves until the bird cries; the spruce is 'spiked', 'like the hand of a clock', and the ant is dead, still, but glowing. What is shown to us is an image of a moment captured in time, a prolonged second for us to visualise. Three types of sound are represented in the poem: 'drips from 
dim leafage, 'the night's murmuring deep in summer's canyon' and 'bird cry'. ${ }^{10}$ The first two sounds do not interrupt the stasis, as they are soft, ongoing background noises. The static mood does not change until the end of the second stanza, but when the bird cries something starts anew, the clouds begin to move again and the static moment is over.

In 'Sista bild' the sound does not transform into something concrete and tangible, but it does not change the poem's stillness either. In our next poem by the Swedish poet Ella Hillbäck (1956, p. 44), however, sound is transformed into an object:

'Det slutgiltiga'

Slättens snö är slutgiltig och allestädes.

Som stillheten. Ropet från fågeln i solnedgången

fastnade på skogarnas krans av spjut.

I denna snö står furornas karyatider.

De som bär templet av mattblå aska

över de förlorade stegen

de bortlupna ordens vägar

och snön som tystnaden djup.

Här är livet kringränt men överlever.

Gårdarna i toppiga nattluvor djupt neddragna

vaknar i sina snögrottor, ett stjärnkast från varandra.

Vinterharen räddar sig över den begravda sjön.

Här är oss mjukt att vara. Låt oss göra en hydda.

Åt tystnaden

låt oss göra en hydda av snö!

'The Final'

The snow on the plain is final and everywhere.

Like the stillness. The cry of the bird in the sunset

got caught on the forest's wreath of spears.

In this snow stand the caryatids of pines.

They who carry the temple of frosted blue ashes

over the lost steps

the ways of the scattered words

and the snow deep as the silence.

Here life is surrounded but survives.

The farms with their pointy nightcaps pulled down

awake in their caves of snow, a star's throw from each other

The winter hare escapes from the buried lake.

Here it is soft to be. Let us make a hut. 
For the silence

let us make a hut out of snow!11

This poem is not structured in a way that imitates our process of decoding, ${ }^{12}$ nor is it as concentrated on one spatially arranged scene as 'Last Picture', even though words such as 'surrounded' and 'a star's throw' can represent spatiality by means of distance and framing. However, the overall mood of the poem is static, a result of the usage of words like 'final', 'stillness' and 'silence'. The snow that is everywhere, embedding nature in a soft, muffling blanket, reinforces the feeling of stasis. There are references to the visual arts as well: "the caryatids of pines' ${ }^{13}$ that 'carry the temple of frosted blue ashes'. By transforming trees into caryatids and the night sky into a temple, the poetic world is perceived as a static, iconic artefact rather than a moving and changing reality. The representation of nature as artefact can also be noted in 'Midnight Turning Point': 'The spruce stands like the hand of a clock', a simile that reminds us of the sprawled flags in 'Last Picture' as well as 'the forest's wreath of spears' in Hillbäck's poem. We can also note that the bird's cry was caught, past tense, which increases the mood of stillness.

In this quiet world, how is representation of sound manifested? What kind of sound can we find? The 'scattered words' are indexical signs of earlier sound, rather than actual sound. The only other sound present in the poem is the bird's cry. And in this poem the sound of the bird is transformed, from invisible sound waves into a tangible and visible object, something that can be 'caught on the forest's wreath of spears'. What the reader sees is individual, but many of us would probably treat the bird call as a synecdoche and create an inner image of a bird in the top of a pine tree. The transformation, I claim, puts the sound on the same level as other elements in the verbal image.

Sound exists in space; it has shape and content. However, since we normally do not see the sound waves the same way as we see snow or trees or birds, a verse like 'The cry of the bird in the sunset/got caught on the forest's wreath of spears' can function as a way to make the invisible visible and thereby keep the reader's role as beholder intact.

\section{Conclusion}

Talking about representation of sound, we can either refer to written letters that represent phonemes or to words that semantically refer to various sounds, such as clinking or barking. Representation of sound in the latter meaning can have (at least) four separate functions or consequences in pictorial poetry: 1) interruption of stasis and introduction of temporal flux; 2) an ongoing background noise which does not interrupt the stasis but instead becomes part of it; 3) a rigid and frozen 
sound that emphasises the static mood in the poem; and 4) a concretised and visible object, placed in the composition, as it were, together with the other elements in the poem. In the second, third and last cases, the mental representation of the conveyed image should have static properties, while in the first case we will probably create a dynamic representation in our mind's eye.

My intention with this article was to include sound in the already intricate, and often investigated, relations of verbal and visual media, to put the intermedial and cognitive tools to the test. Can the game include a third player, as it were? Where does sound fit in? My results show that a poem can be pictorial and still represent sound, even if some kinds of sound need to be transformed into something concrete and tangible. I have shown this partly by means of cognitive science, but this approach should not be interpreted as an effort to present some kind of proof that my theories are correct. Evidence is not the main concern here; literature is not an exact science. However, if we as literary researchers are interested in - and I hope we are - broadening and deepening our knowledge of how literature works, then cognitive science can be one of many ways to go. It does not mean that we abandon the text, quite the opposite. Literary studies, and specifically intermedial literary studies, are often highly theoretical. Using cognitive research can function as a concretisation of abstract ideas, as a motivator to go back to the text, to perform another close reading of it; because our reactions as readers depend not only on our individual experiences, but also on the structure of the text. The formalists, the structuralists and the narratologists have already shown that, and the intermedial cognitive approach deals with the same thing, only from a different angle. Cognitive science will not provide us with the ultimate answers, but it will perhaps make us better equipped to ask the questions.

\section{References}

Adams, S.J. (1989). The Noisiest Novel ever Written: The Soundscape of Henry Roth's Call it Sleep. Twentieth Century Literature, 35(1), 43-64.

Bender, J.B. (1972). Spenser and Literary Pictorialism. Princeton, New Jersey: Princeton University Press.

Bergen, B., \& Wheeler, K. (2009). Grammatical Aspect and Mental Simulation. Brain \& Language, 112(2010), 150-158.

Bishop, E. (2011). Poems. New York: Farrar, Strauss and Giroux.

Borst, G., \& Kosslyn, S. (2008). Visual Mental Imagery and Visual Perception: Structural Equivalence Revealed by Scanning Processes. Memory \& Cognition, 36(4), 849-862.

Bower, G.H., \& Morrow, D.G. (1990). Mental Models in Narrative Comprehension. Science, 247(4938), 44-48.

Elleström, L. (2010). The Modalities of Media: A Model for Understanding Intermedial Relations. In: Elleström, L. (Ed.), Media Borders, Mulimodality and Intermediality (pp. 11-50). Basingstoke: Palgrave Macmillan. 
Enns, J.T. (2004). The thinking eye, the seeing brain: explorations in visual cognition. New York: W.W. Norton.

Esrock, E.J. (1994). The Reader's eye; Visual Imaging as Reader Response. Baltimore: John Hopkins University Press.

Glenberg, A.M., Mayer, M., \& Lindem, K. (1987). Mental Models Contribute to Foregrounding during Text Comprehension. Journal of Memory and Language, 26(1), 69-83.

Gosetti-Ferencei, J.A. (2007). Interstitial Space in Rilke's Short Prose Works. The German Quarterly, 80(3), 302-324.

Gustafsson, L. (1998). Valda skrifter. Stockholm: Natur och Kultur.

Hagstrum, J.H. (1958). The Sister Arts. The Tradition of Literary Pictorialism and English Poetry from Dryden to Gray. Chicago: University of Chicago Press.

Halter, P. (1999). Iconic Rendering of Motion and Process in the Poetry of William Carlos Williams. In: Nänny, M., \& Fischer, O. (Eds.), Form Miming Meaning (pp. 235-250). Philadelphia: John Benjamins Publishing Company.

Heffernan, J.A.W. (1993). Museum of Words. The Poetics of Ekphrasis from Homer to Ashbery. Chicago, London: The University of Chicago Press.

Hillbäck, E. (1956). Det älskansvärda. Stockholm: Bonniers.

Holšánová, J. (2008). Discourse, Vision and Cognition. Amsterdam, Philadelphia: John Benjamins Publishing Company.

Hustvedt, S. (2005). The Mysteries of the Rectangle; Essays on Painting. New York: Princeton Architectural Press.

Kozhevnikov M., Kosslyn S., \& Shephard, J. (2005). Spatial Versus Object Visualizers: A Characterization of Visual Cognitive Style. Memory and Cognition, 33(4), 710-726.

Levinson, J., \& Alperson, P. (1991). What is a Temporal Art? Midwest Studies in Philosophy, 16(1), 439-450.

Lyas, C. (2001). Representation in Literature. In: Sukla, A.C.H. (Ed.), Art and Representation (pp. 175193). Westport, Connecticut, London: Praeger.

Mitchell, W.J.T. (2005). There Are No Visual Media. Journal of Visual Culture, 4(2), 257-266.

Reddy, L., Tsuchiya, N., \& Serre, T. (2009). Reading the Mind's Eye: Decoding Category Information During Mental Imagery. NeuroImage, 50 (2010), 818-825.

Richardson, D. \& Matlock, T. (2007). The Integration of Figurative Language and Static Depictions: An Eye Movement Study of Fictive Motion. Cognition, 102(1), 129-138.

Robillard, V. (2007). Still Chasing Down the Greased Pig. In: Arvidson, J., Askander, M., Bruhn, J., \& Führer (Eds.). Changing Borders. Contemporary Positions in Intermediality (pp. 256-281). Lund: Intermedia Studies Press.

Stevens, Wallace (1990). The Collected Poems. New York: Vintage Books; Toronto: Random House of Canada Limited

Söderström, H. (2003). Bilden som byggsten. Om Lars Gustafssons poetik och lyriska praktik. Stockholm, Stehag: Symposium.

Torgovnick, M. (1985). The Visual Arts, Pictorialism, and the Novel. James, Lawrence, and Woolf. Princeton, New Jersey: Princeton University Press.

Tranströmer, T. (2002). Samlade dikter 1954-1996. Stockholm: Bonniers.

Tranströmer, T. (2006). The Great Enigma. New Collected Poems. Trans. R. Fulton. New York: New Directions Publishing Corporations.

Vandsø, A. (2011). Listening to the world. SoundEffects, 1(1), 67-81.

Zwaan, R.A. (2003). The immersed Experiencer: Toward an Embodied Theory of Language Comprehension. Psychology of Learning and Motivation, 44(2003), 35-62.

Zwaan, R.A., \& Radvansky, G.A. (1998). Situation Models in Language Comprehension and Memory. Psychological Bulletin, 113(2), 162-185. 


\section{Notes}

1 I would like to point out that concretisation of sound is not a phenomenon restricted to pictorial texts. In this article, however, my interest in concretisation of sound is limited to its presence in pictorial poetry.

2 The theoretical field that uses cognitive science as an analytical tool for understanding our reception of literature is called cognitive poetics. Scholars like Reuven Tsur and Peter Stockwell are active in this field, which gains more and more interest, not least from intermedial researchers, maybe because it offers new insights on literature and reading. In this article, however, my aim is to apply cognitive research results directly on the analysed poems, and not, as it were, go via the field of cognitive poetics.

3 On the subject of inviting the reader to visualise, see for example Ellen J. Esrock (1994). On the subject of framing by means of repeating, see for example Valerie Robillard (2007).

4 Robillard (2007, p. 262) claims that the ekphrastic writer is 'first and foremost a viewer'. I would like to add that the reader of an ekphrastic poem is a viewer as well, and that the writer is not only a viewer, but a co-creator.

5 The notion that sound can be 'seen' is of course not new. One author who treated sound as space is Rainer Maria Rilke. 'In "Ur-geräusch" Rilke returns to the relation between space and sound, rediscovering the possibilities of "hearing" space' (Gosetti-Ferencei, 2007, p. 315).

6 Bishop's poems are often pictorial. In this example, however, there is no pictoriality, but the example is chosen to illustrate how sound can be concretised.

7 Concretised sound can sometimes be metaphors, as in for example Wallace Stevens' (1990, p. 376) poem 'Credences of summer', eighth stanza: 'The trumpet of morning blows in the clouds and/through/ The sky. It is the visible announced,/It is the more than visible, the more/Than sharp, illustrious scene. The trumpet cries/This is the successor of the invisible'.

8 My translation.

9 See Robillard's analysis of 'The Hunters in the Snow' by William Carlos Williams (Robillard, 2007, p. 264).

10 The words 'bird cry' have another signification in English compared to the Swedish original 'fågel skrek'. 'Bird cry' is a noun, although here it should probably be interpreted as 'bird cried'. In both Swedish and English the sentence is formally incorrect. The Swedish original lacks the correct definite form 'fageln skrek', and the English translation lacks the definite article 'the'. Furthermore, the English translation uses present tense, 'cry', and not the original past tense, 'cried', and cry lacks the formally correct verbal form, third person singular. By excluding the definite form, the represented sound seems more sudden and direct. Fulton's translation choices convey the same immediacy in English.

11 My translation.

12 An enlightening article on imitations of decoding processes is 'Iconic Rendering of Motion and Process in the Poetry of William Carlos Williams' by Peter Halter (1999).

13 Caryatids are columns in the shape of women. 